\title{
Notas sobre a "Piedra" brasileira
}

\author{
Pelo Dr, Floriano paulo de Almeida \\ trabalho do laboratorio de Microbiologia \\ da Faculdade de Medicina de São Paulo.
}

\begin{abstract}
C OM os nomes de "Piedra", trichomycose nodular, tinha nodosa, trichosporia, etc., designa-se uma mycose benigna e relátivamente commum na classe dos estudantes. Pelo que se deprehende da observação dos autores nacionaes, que do assumpto se têm occupado, cerca de $80 \%$ dos casos de "Piedra" encontrados no Brasil são de estudantes. Não raro surgem pequenas epidemias em collegios, principalmente em internatos, consoante observações de Bruno Lobo no Rio de Janeiro e José de Assis no Rio Grande do Sul.
\end{abstract}

Esta mycose, descripta pela primeira vez na Colombia, onde em certas regióes é relativamente frequente entre as mulheres, foi depois encontrada na Europa. Antes, porém, dos estudos de Nicolau Ozorio e Pozada Arango em 1876 na Colombia,. já Beigel, no Velho Continente, havia descripto a "molestia dos chinós", attribuindo-lhe uma natureza cryptogamica, contestada porém por seus contemporaneos. Com o material enviado pelos autores colombianos foram feitos optimos trabalhos por Desenne, Juhel Renoy, Morris, Lyon, Behrend, provando á saciedade a natureza vegetal dos nodulos parasitarios. Em contraposição á "Piedra colombica" receberam os casos europeus a designação de "Piedra nostras" No Brasil devemos a Pedro Severiano de Magalhães a publicação, em 1901, do primeiro caso de Piedra entre nós occorrido. Chronologicamente, porém, a primazia da verificação dessa mycose pertence a Victor Godinho, que com Francisco Fajardo estudou um caso de sua clinica em 1896.

Este caso só foi dado á publicidade em 1906, depois da publicação por Severiano de Magalhães de seu "Novo caso de Piedra"

Em 1911, Parreiras Horta, do Instituto Oswaldo Cruz, em optima monographia "Sobre uma nova fórma de Piedra", estuda cuidadosamente o assumpto, descrevendo, nos casos brasileiros que estudou, kystos até então não observados nos casos indigenas, nem nos extrangeiros. Desses estudos resultou a creação de uma 


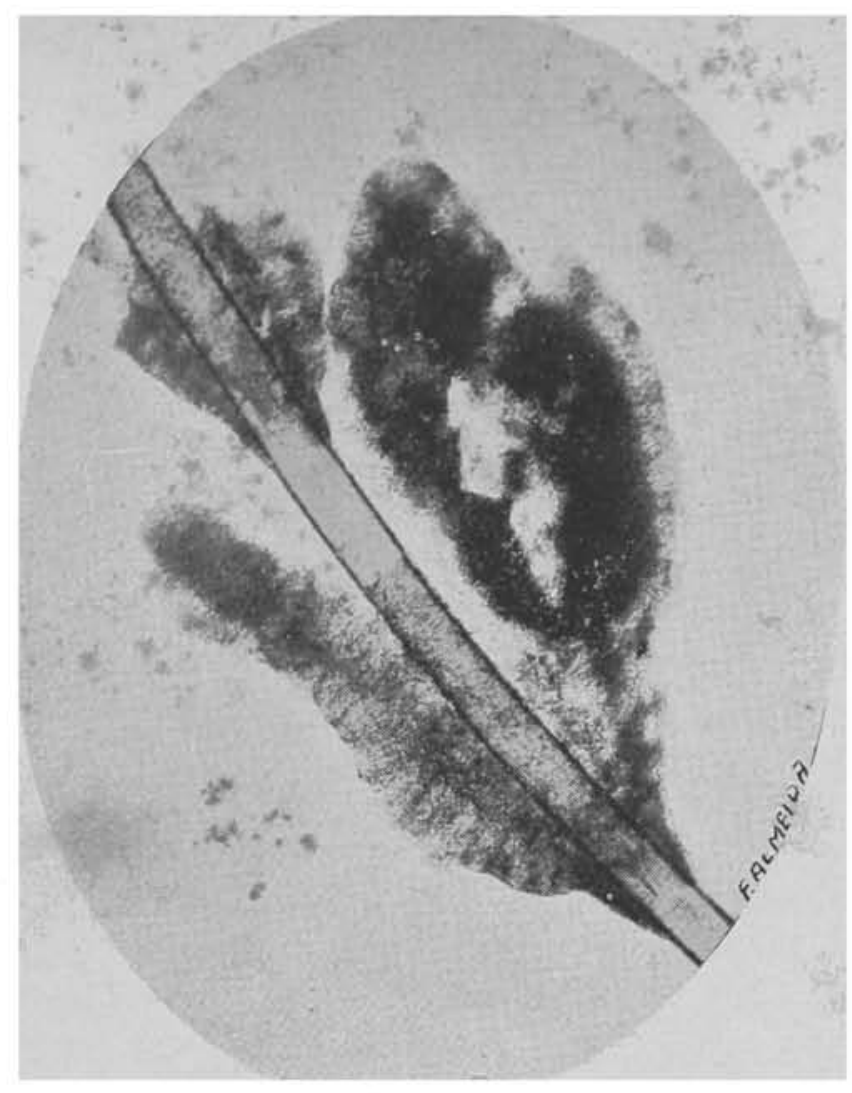

FIG. I. - Cabello com (nodulo piedrico) parcialmente destacado.

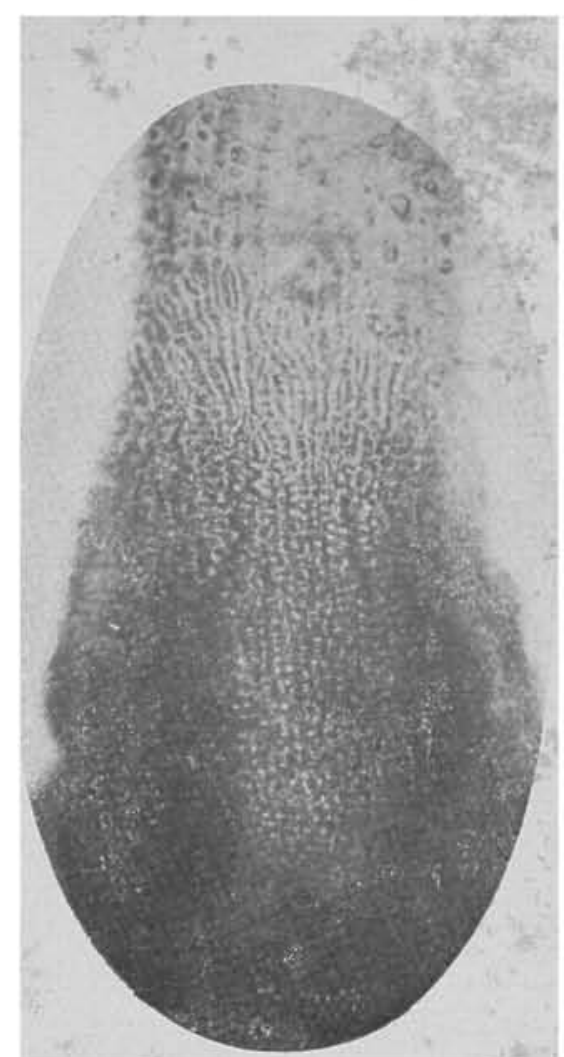

FIG. II. - Mycelios do cogumelo. (Piedraia hortai) invadindo o cabello.

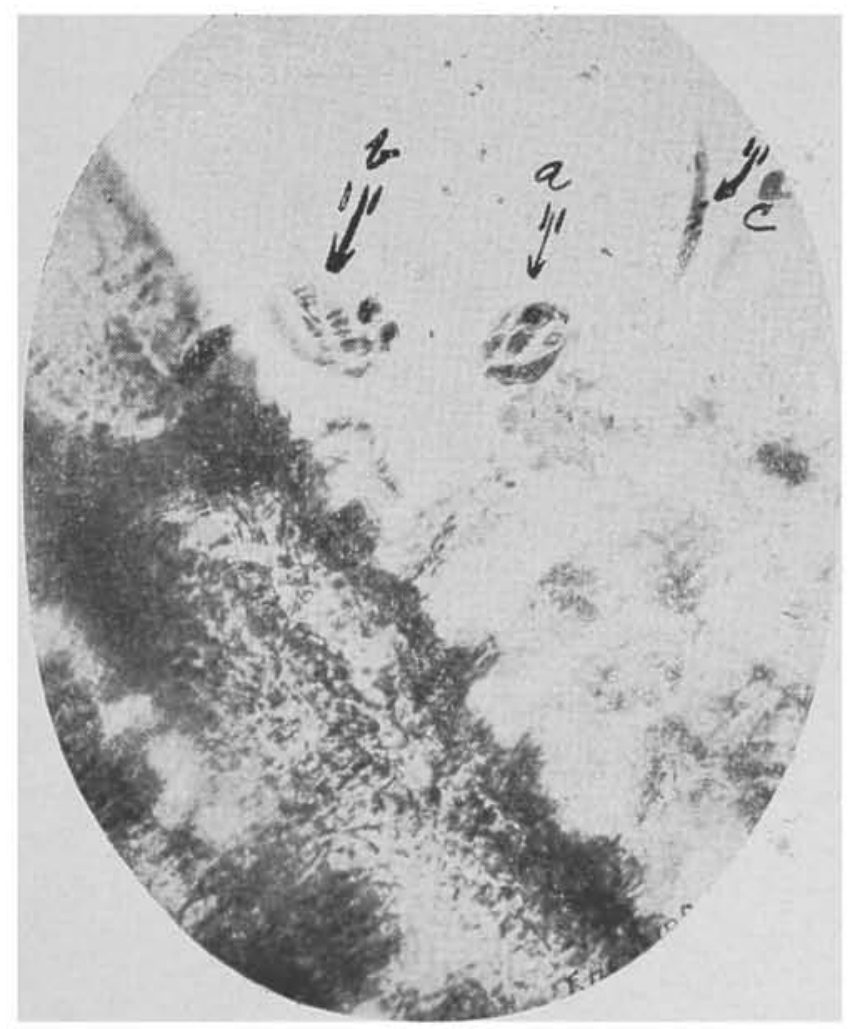

FiG. III. - (a) kysto intacto, livre do nodulo, (b) kysto ligeiramente desteito, (c) elemento fusiforme livre.

Este preparado foi corado pelo Tricorante de Guegrien. (Bleu coton, Sudan III, tintura de iodo e acido lacico). 

nova especie para a Piedra brasileira, denominada Trichosporum hortai, Brumpt, 1913, em contraposição ao Trichosporum giganteum, Beherend, 1890, productor da "Piedra colombica"

Estudos recentemente feitos no Instituto Oswaldo Cruz, por Olympio da Fonseca, filho e Arêa Leão, permittiram a esses autores observar, nas culturas dos casos brasileiros de Piedra, as memas formações fusiformes descriptas por Horta, nos nodulos. A presença desses elementos, nas culturas e nas fórmas parasitarias, levou os autores citados a estabelecer um novo genero para a Piedra brasileira, propondo a designação de Piedraia hortai (Brumpt, 1913).

O diagnostico da mycose de que ora tratamos é feito com relativa facilidade. Os cabellos e mais raramente os pellos do bigode e da barba apresentam pequenos nodulos escuros, alcançando os maiores o volume da cabeça de um alfinete pequeno.

Quando o parasitismo se encontra localisado a uma parte dos cabellos, os nodulos, com sua coloração quasi negra, conferem áquelles um aspecto que a certa distancia simula uma mancha de pixe, mórmente nos cabellos louros. Um exame cuidadoso permittenos verificar a existencia dos pequenos nodulos em numero, ás vezes, consideravel, em um mesmo cabello. A' palpação, temos a sensação de areia fina.' A passagem do pente determina um leve ruido, produzido pelos nodulos duros e resistentes. A denominação popular de Piedra, pedra, dada á mycose define perfeitamente a rijeza desses nodulos. Quando bem desenvolvidos esses nodulos envolvem completamente o cabello que no entretanto nada perde de sua vitalidade e resistencia. (Fig. 1).

Para exame microscopico tratamos o cabello com potassa a $40 \%$ ou lactophenol, entre lamina e laminula, aquecemos e levamos ao microscopio. $\mathrm{O}$ cabello assim clareado mostra-nos nitidamente a constituição do nodulo, que em sua porção peripherica dá-nos uma idéa bem nitida de sua natureza cryptogamica. Vêmos ahi um mycelio septado extremamente abundante, dando a impressão de um mosaico. (Fig. 2). A forma das cellulas resultantes da segmentação das hyphas é ligeiramente polyedrica, ás vezes mais ou menos oval, arredondada ou alongada. Na parte mais espessa do nodulo encontramos as formaçôes kysticas tão bem descriptas no trabalho de Parreiras Horta. Esses kystos são constituidos por elementos fusiformes (Fig. 3), tendo nas extremidades um appendice flageliforme. A presença desses kystos é constante nos casos de Piedra observados no Brasil, conforme as observações de Parreiras Horta, Fonseca, filho, Abilio de Castro, José de Assis e as nossas. Ultimamente, foram assignalados nos casos observados no Paraguay por Delamari e Gatti. 
Para obtermos culturas é bastante tratar os cabellos pelo alcool, ether ou chloroformio e semearmos os nodulos nos meios communs mycologicos, principalmente nos de prova de Sabouraud, maltosado ou glycosado.

Os pedaços de cabellos com nodulos semeados dão no fim de alguns dias os primeiros esboços de desenvolvimento. Em torno do nodulo apparecem pequenas expansões que aos poucos envolvemno completamente. As colonias são de coloração escura, quasi negra, principalmente nos casos ricos de kystos. Naquelles em que a presença dessas formações é escassa as colonias tomam um aspecto semelhante ao encontrado nas culturas da "Piedra nostras", segundo verificações de Parreiras Horta. As colonias pigmentadas, negras, dos casos nacionaes são glutinosas, resistentes, duras, e fortemente adherentes ao meio de cultura.

No que respeita ao tratamento dessa mycose pouco se tem a dizer. E' sufficiente fazer friç̧ões ou lavagens da cabeça com soluções antisepticas, como o sublimado a $1 \%$, para se obter em pouco tempo a cura completa. O córte rente dos cabellos facilita a cura, porém, não é necessario. 